\title{
Analysis of Bone Mineral Density in Turner Syndrome -Longitudinal Data-
}

\author{
Hisafumi Matsuoka and Mitsunori Murata
}

Department of Pediatrics, Tokyo Women's Medical College Daini Hospital, Tokyo, Japan

\begin{abstract}
The bone mineral density of the 2nd metacarpal of the left hand was measured by the Digital Image Processing Method (DIP) in five Japanese children with Turner syndrome. We made growth curves of bone mineral density, based on bone age, which were measured by the TW2 RUS method. In all cases bone mineral density showed increased values for 2-5 years, but SD scores were not much changed at any measuring-point after GH-treatment. These data indicate that GH treatment may have no effect on bone mineral density.
\end{abstract}

Key words: Turner syndrome, hGH therapy, bone mineral density, DIP method

\section{Introduction}

We report five cases of Turner syndrome which were treated with growth hormone. The effects of growth hormone on bone mineral density were studied for $2-5$ years. We obtained longitudinal data of bone mineral density for all cases.

\section{Subjects and Methods}

Measurement of bone mineral density by the DIP method was performed on five cases of Turner syndrome. The bone chosen for this method was the 2nd metacarpal of the left

Correspondence: Dr. Hisafumi Matsuoka, Department of Pediatrics, Tokyo Women's Medical College Daini Hospital, 2-1-10, Nishiogu, Arakawaku, Tokyo 116 Japan hand. Other parameters such as bone age, chronological age and body height were also measured, and growth curves of bone mineral density were obtained. All cases were of short stature and the average height SD score was -2.9 . [Table 1]

Table 1. Patient Data

\begin{tabular}{|lrr|rrr|rrrr|}
\hline Case 1 & & & \multicolumn{1}{l|}{ Case2 } & & Case3 & \\
\hline CA & RUS & BMD-SD & CA & RUS & BMD-SD & CA & RUS & BMD-SD \\
\hline 3.45 & 2.48 & 11.97 & 9.7 & -1.78 & 6.02 & 7.7 & 0.99 \\
4.28 & 1.20 & 12.37 & 10.8 & -1.15 & 6.61 & 8.6 & 0.41 \\
4.55 & -0.76 & 12.61 & 10.9 & -3.54 & 6.81 & 8.8 & -0.71 \\
4.99 & & 0.90 & 12.97 & 10.9 & -2.58 & 7.36 & 8.8 & -0.06 \\
5.45 & 3.3 & -0.85 & 13.43 & 10.9 & -2.28 & 7.64 & 9.4 & 0.20 \\
5.68 & 4.7 & -0.44 & 13.94 & 11.3 & -2.41 & 8.2 & 10 & 0.76 \\
& & & 14.36 & 11.8 & -1.94 & 8.62 & 10.1 & -0.98 \\
\hline
\end{tabular}

\begin{tabular}{|c|c|c|c|c|c|}
\hline \multicolumn{3}{|l|}{ Case 4} & \multicolumn{3}{|l|}{ Case 5} \\
\hline $\mathrm{CA}$ & RUS & BMD-SD & CA & RUS & BMD-SD \\
\hline 5.4 & & 1.25 & 4.02 & 3.7 & 0.45 \\
\hline 5.71 & & 2.83 & 4.49 & 5.2 & 1.74 \\
\hline 5.92 & 3.3 & 1.19 & 5.14 & 5.4 & 0.11 \\
\hline 6.41 & 5.2 & 3.44 & 6.49 & 7 & 0.28 \\
\hline 6.76 & 5.4 & 1.07 & 6.76 & 7.1 & -0.71 \\
\hline 7.42 & 6.3 & 2.84 & 7.11 & 7.6 & -1.64 \\
\hline 7.95 & 7.2 & 1.16 & 7.36 & 8 & 0.60 \\
\hline & & & 8.01 & 9.1 & 0.60 \\
\hline
\end{tabular}




\section{Results}

Fig. 1 shows growth curves of bone mineral density based on chronological age. Basal mineral density was low in the pubertal period, but less so in the prepubertal period. In all cases bone mineral density values increased, but SD scores were not much changed at any measuring-point. Fig. 2 shows growth curves of bone mineral density based on bone age, measured by the TW2 RUS method. Bone age is based on the Japanese standard. It shows almost the same pattern as Fig. 1 but in the pubertal period it is not low. In the one case in which bone mineral density was low, bone age was retarded. Because of this retardation her bone mineral density was low in the pubertal period, but in Fig. 2 we cannot see the low density.

\section{Discussion}

Bone mineral density increases significantly with age in childhood, with a steeper increase at the time of puberty. [1] According to Saggese et al., GH-deficient children show significant reduction of bone mineral density for their chronologic, statural, and bone ages, but bone mineral density significantly improves after 12 months of $\mathrm{GH}$ treatment. [2, $3,4]$ Using two figures, we show longitudinal data of bone mineral density in Japanese cases of Turner syndrome. When bone ages are substituted for chronological ages, almost all bone mineral densities are distributed within the normal range. After the growth hormone therapy, SD scores did not change for a few years. These results suggest that we have to estimate the bone age when measuring

\section{$\Sigma G S / D$}

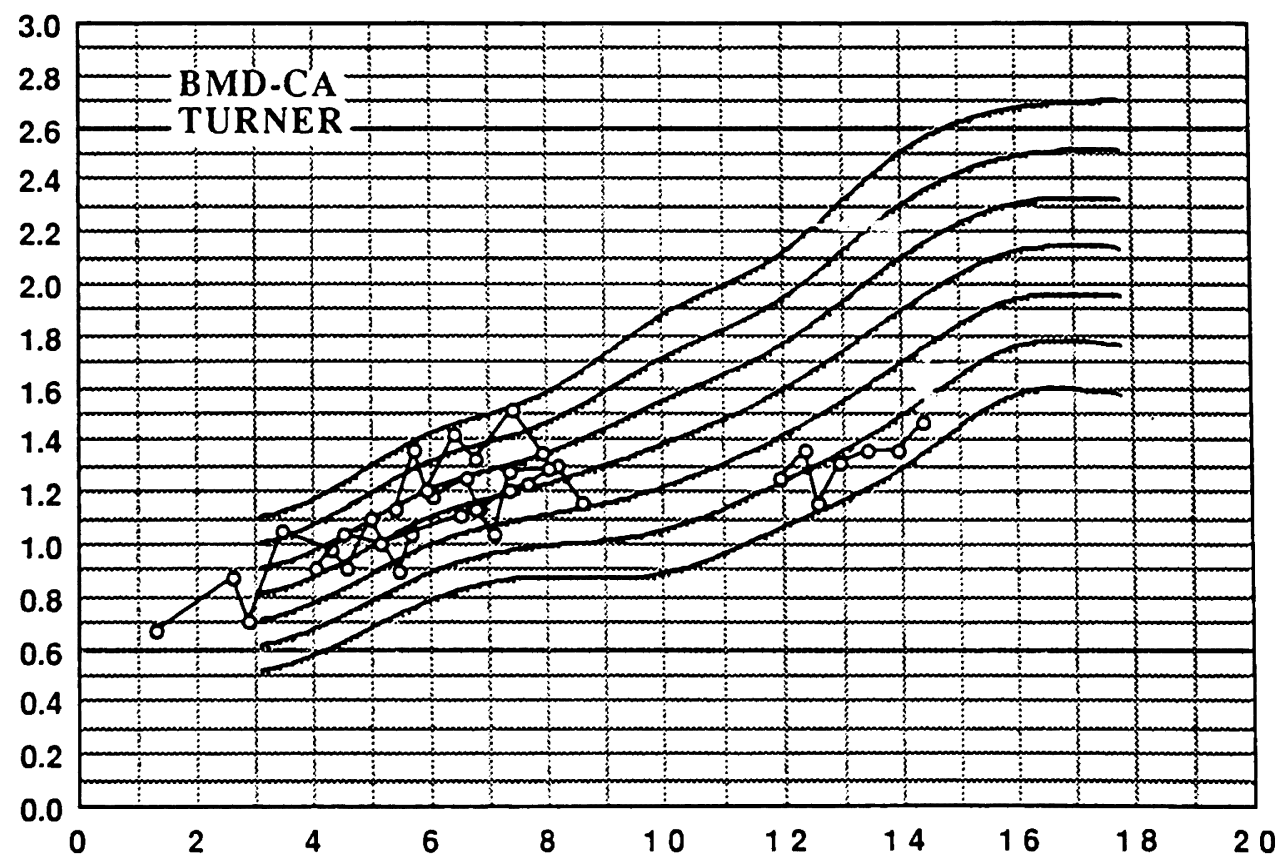

Fig. 1. BMD SD score changes after GH treatment (CA) 
bone mineral density and that growth hormone has no effect on bone mineral density.

\section{References}

1. Gastre C, Braillon P, David L, Cochat P, Meunier PJ, Delmas PD. Measurement of bone mineral content of the lumbar spine by dual energy x-ray absorption in normal children: correlations with growth parameters. J Clin Endocrinol Metab. 1990; 70: 1330-3.

2. Saggese G, Barancelli GI, Bertelloni S, Cinquanta L, Nero GD. Effects of longterm treatment with growth hormone on bone and mineral metabolism in children with growth hormone deficiency. J Pediatrics. 1993; 122: 37-45.

3. Kaufman JM, Taelman P, Vermeulen A, Vandeweghe $M$. Bone mineral status in growth hormone-deficient males with isolated and multiple pituitary deficiencies of childhood onset. J. Clin Endocrinol Metab. 1992; 74: 118-23.

4. Degerblad M, Elgindy N, Hall K, Sjoberg $\mathrm{HE}$, Thoren M. Potent effect of recombinant growth hormone on bone mineral density and body composition in adults with panhypopituitarism. Acta Endocrinologica. 1992; 126: 387-93.

\section{$\Sigma G S / D$}

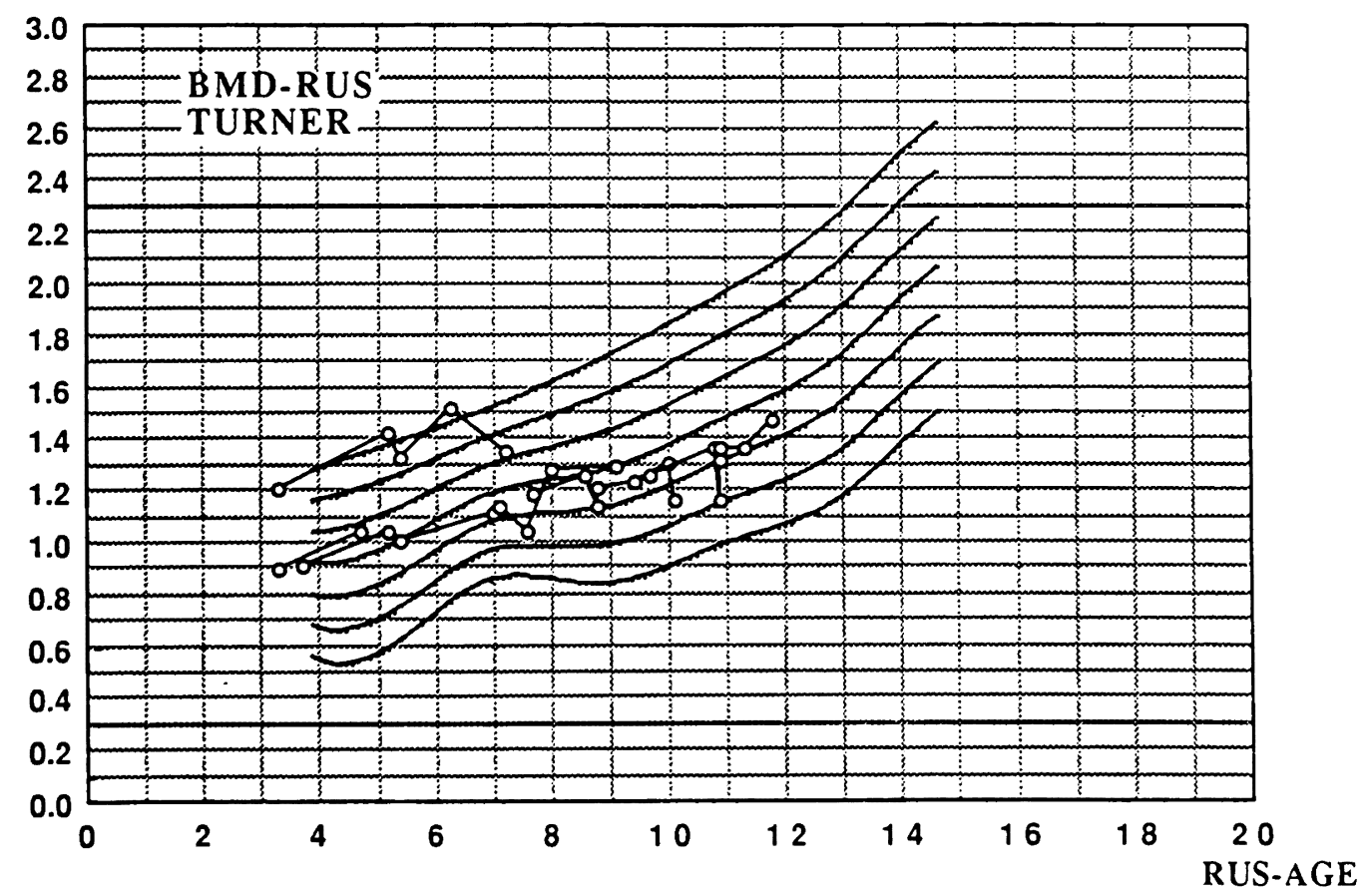

Fig. 2. BMD SD score changes after GH treatment (RUS) 